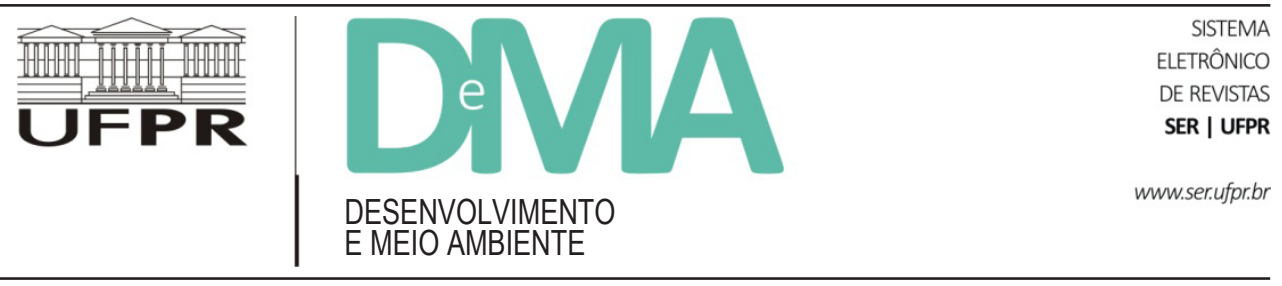

\title{
As relações econômicas e a gestão compartilhada de recursos comuns: o caso da pesca marinha em Pontal do Paraná, Sul do Brasil
}

\section{Economic Relations and the Co-Management of Common Resources: the Case of Marine Fisheries in Pontal do Paraná, Southern Brazil}

\author{
Guilherme Augusto CALDEIRA ${ }^{1 *}$, Naína PIERRI ${ }^{1,2}$ \\ ${ }^{1}$ Programa de Pós Graduação em Meio Ambiente e Desenvolvimento (PPGMADE), Universidade Federal do Paraná (UFPR), Curitiba, PR, Brasil. \\ ${ }^{2}$ Centro de Estudos do Mar (CEM), Universidade Federal do Paraná (UFPR), Pontal do Sul, PR, Brasil. \\ *E-mail de contato: guicaldeirasocioambiental@gmail.com
}

Artigo recebido em 31 de março de 2014, versão final aceita em 15 de setembro de 2014.

RESUMO Este artigo aborda a importância da consideração das dinâmicas econômicas nos processos de gestão compartilhada da pesca. A discussão se baseia em um diagnóstico dos principais condicionantes de resultados socioeconômicos e ecológicos da atividade no município de Pontal do Paraná, litoral do Paraná, no Sul do Brasil. A análise foi orientada por um modelo sistêmico que, à luz da economia política marxista, integrou elementos da organização social da produção a modelos que investigam o papel das instituições na criação de incentivos capazes de moldar o comportamento dos usuários e, consequentemente, influenciar os resultados obtidos com o uso de recursos comuns. A abordagem se mostrou extremamente útil para a compreensão da influência das dinâmicas econômicas na estrutura de incentivos ao comportamento dos pescadores e na configuração de maus resultados obtidos com a pesca, tais como a degradação da base de recursos, diferenciação social e pobreza. Além disso, a abordagem apontou caminhos profícuos para incorporar a dimensão econômica ao processo de gestão compartilhada em busca de uma atividade economicamente eficiente, socialmente justa e ecologicamente prudente.

Palavras-chave: pesca de pequena escala; gestão compartilhada de recursos comuns; instituições; economia política marxista; organização social da produção.

ABSTRACT This article discusses the importance of considering the economic dynamics in fisheries co-management. The discussion is based on a diagnosis of the main determinants of socioeconomic and ecological results of this activity in the municipality of Pontal do Paraná, on the coast of Paraná state, Southern Brazil. The analysis was guided by a systemic model that, in the light of the Marxist political economy, has incorporated elements of social organization of production to models that investigate the role of institutions in creating incentives to shape users' behavior and, hence, determine the results obtained with the use of common resources. The 
approach proved extremely useful to understand the influence of economic dynamics in incentives to the behavior of fishermen and on the configuration of undesired results on fishing activity, such as the degradation of the natural resource base, social differentiation and poverty. Moreover, the approach pointed fruitful ways to incorporate the economic dimension into the co-management process in search of an economically efficient, socially fair and ecologically prudent activity.

Keywords: small-scale fisheries; co-management of common resources; institutions; Marxist political economy; social organization of production.

\section{Introdução}

No mundo todo, especialmente a partir da década de 1990, a constatação das limitações da gestão pesqueira convencional - marcada pelo enfoque biológico-reducionista e pela centralização dos processos de tomada de decisão nas mãos do Estado - tem contribuído para o surgimento de uma nova forma de abordagem: a gestão compartilhada ou cogestão, definida como uma forma de parceria na qual o governo, os usuários de recursos naturais em nível local e outros atores (como organizações não governamentais, universidades e instituições de pesquisa) compartilham poder e responsabilidade na gestão da pesca (Pomeroy \& Williams, 1994; Berkes et al., 2001; Pomeroy \& Rivera-Guieb, 2006).

Com base em formulações teóricas e conceituais sobre a gestão dos recursos naturais de uso comum, essa nova abordagem reconhece que, em determinadas condições, os usuários dos recursos são capazes de se organizar e de empreender modalidades de apropriação economicamente eficientes, socialmente equitativas e que, considerando horizontes de longo prazo, respeitem os limites necessários para a sustentabilidade da base de recursos naturais. Do mesmo modo, assume-se que esses resultados estão estreitamente ligados à construção, bom funcionamento e sobrevivência das instituições, entendidas como um conjunto de regras ou códigos de conduta socialmente construídos com o objetivo de moldar o comportamento dos usuários e promover estratégias cooperativas e coordenadas para o manejo dos recursos (Ostrom, 1990; 1992; Thomson et al., 1992).

Com o objetivo de analisar as condições e subsidiar estratégias de gestão compartilhada, foi elaborado um diagnóstico da pesca no município de Pontal do Paraná, no litoral do Paraná, sul do Brasil. O diagnóstico foi es- truturado com base em modelos analíticos amplamente utilizados para o estudo de sistemas de gestão de recursos comuns, inclusive recursos pesqueiros (Oakerson, 1992; ICLARM, 1998). Em linhas gerais, estes procuram analisar de que forma as instituições interagem com variáveis contextuais criando uma estrutura de incentivos ao comportamento dos usuários (padrões de interação), os quais são fundamentais para a configuração de resultados (medidos em termos de eficiência, equidade e sustentabilidade na exploração dos recursos). Entre as variáveis do contexto consideradas por esses modelos estão: características dos usuários (tamanho do grupo, coesão social, tradição em ação coletiva, etc.); características dos recursos (físicas e biológicas), tecnologia utilizada (capacidade de subtração e compatibilidade com a conservação da base de recursos); atributos de mercado (oferta e demanda); e fatores externos (macroeconômicos, políticos, naturais, etc.).

Para aprofundar o estudo das dinâmicas econômicas envolvidas, o diagnóstico incluiu variáveis referentes à organização social da produção pesqueira local, analisados à luz da economia política marxista (Marx, 1987; Foladori \& Melazzi, 2009). Entre os elementos considerados estão: as relações de concorrência mercantil, as condições de produção e inserção no mercado, as relações sociais estabelecidas a partir da propriedade privada dos meios de produção, o processo de diferenciação social, as estratégias de comercialização e a atuação do capital comercial.

Neste artigo, procura-se demonstrar a influência das dinâmicas econômicas no comportamento dos pescadores enquanto produtores mercantis e na configuração dos resultados socioeconômicos e ecológicos obtidos com a pesca no município. Além disso, são apontados possíveis caminhos para inserir a discussão sobre as 
formas de organização social da produção pesqueira no processo de gestão compartilhada da atividade.

\section{Metodologia}

As informações utilizadas na pesquisa foram obtidas por meio do levantamento bibliográfico e de dados primários. Os dados primários foram obtidos de setembro de 2006 a setembro de 2009, mediante a aplicação de técnicas de pesquisa das ciências sociais, incluindo entrevistas semiestruturadas, conversas informais, observação direta, e observação participante (Quivy \& Campenhoudt, 1992; Berkes et al., 2001; Seixas, 2005).

As entrevistas foram aplicadas junto a pescadores, comerciantes de pescado, técnicos da EMATER - Instituto Paranaense de Assistência Técnica e Extensão Rural, e um técnico do IBAMA - Instituto Brasileiro do Meio Ambiente e dos Recursos Naturais Renováveis.

As entrevistas com pescadores foram divididas em duas categorias: a entrevista geral e as entrevistas centradas em temas específicos ou focused interviews (Quivy \& Campenhoudt, 1992). A entrevista geral foi aplicada junto a 10 pescadores, e foi balizada por um roteiro dividido em três grandes temas: arranjos produtivos da pesca, manejo dos recursos pesqueiros e indicadores de resultados obtidos com a pesca. Já as entrevistas centradas em temas específicos visavam aprofundar o estudo de algumas questões e conhecer eventos ou fenômenos a partir da percepção daqueles que os vivenciaram ou assistiam de perto. Foram utilizados dois roteiros de entrevista. Um deles, aplicado junto a cinco informantes, abordava o tema das estratégias de cooperação ou ação coletiva para a resolução dos problemas da pesca (experiências de criação e funcionamento de organizações econômicas ou de representação da categoria, dificuldades e potencialidades para organização social). O outro roteiro, aplicado junto a sete informantes, era destinado a uma melhor compreensão da condição socioeconômica de diferentes estratos de pescadores (rendimento econômico, patrimônio, grau de satisfação socioeconômica do pescador, instrumentos de produção disponíveis, calendário pesqueiro, formas de comercialização e outras fontes de rendimento econômico). ${ }^{1}$

As entrevistas com comerciantes foram estruturadas em torno dos seguintes tópicos: fornecedores e compradores, atividades de beneficiamento e processamento realizadas, preços de compra e venda do pescado e dificuldades enfrentadas. Foram ouvidos cinco informantes, com tempo de envolvimento com a atividade variando entre cinco e quarenta anos.

Foram entrevistados dois técnicos da EMATER. Uma das entrevistas contemplou informações sobre a atuação da instituição no âmbito da pesca do município (ações desenvolvidas, infraestrutura e recursos humanos e dificuldades enfrentadas). A outra entrevista teve como objetivo levantar informações sobre a COOPESPAR Cooperativa dos Pescadores Artesanais do Litoral do Paraná, uma experiência de organização para a venda em comum de pescado que envolveu pescadores de todo o litoral do estado nas décadas de 1980 e 1990 (processo de criação, estrutura administrativa e organizacional, comunidades ou grupos de pescadores envolvidos, infraestrutura, serviços prestados, estratégias de comercialização, atuação dos pescadores do município e dificuldades enfrentadas pela organização). A entrevista foi realizada junto a um técnico que participou ativamente do empreendimento. Ao longo do procedimento, foram consultados documentos como estatutos da organização, atas de reuniões e plantas das instalações.

A entrevista com o técnico do IBAMA (biólogo chefe do escritório regional) abordou questões relativas ao manejo dos recursos pesqueiros do litoral paranaense, e foi guiada por um roteiro que continha dois tópicos principais. O primeiro abordava o processo de criação das regras operacionais que incidem sobre a pesca em Pontal do Paraná (atribuições e atuação dos órgãos do governo, trâmites necessários, participação dos pescadores do município e descrição do processo de criação de algumas das normas de maior repercussão na pesca local). O segundo tópico abordou a questão da fiscalização (atribuições e atuação dos órgãos envolvidos, infraestrutura e recursos humanos disponíveis, estratégias utilizadas, papel dos usuários dos recursos, autuações

\footnotetext{
${ }^{1}$ Todas as entrevistas foram aplicadas junto a pessoas apontadas como lideranças e/ou com conhecimento suficiente para fornecer informações sobre a pesca na localidade em que residem. O tempo aproximado de envolvimento dos entrevistados com a pesca variou entre 25 e 60 anos.
} 
mais frequentes e dificuldades enfrentadas pelos agentes de fiscalização). Durante a entrevista, foram acessados materiais como autos de infração e documentação relativa à criação de algumas normas.

Os procedimentos de observação direta ocorreram em 39 incursões à orla e aos portos de pesca, bem como em 10 reuniões públicas no âmbito da gestão pesqueira no litoral do Paraná. Também foram realizados 11 procedimentos de observação participante em pescarias. Sempre que oportuno, durante as saídas de campo para a observação direta ou aplicação de entrevistas, ocorreram conversas informais com pescadores, as quais giraram em torno de diversos temas pertinentes à pesquisa.

\section{3. $O$ contexto socioecológico}

O litoral paranaense abrange os municípios de Paranaguá, Antonina, Morretes, Guaraqueçaba, Guaratuba, Matinhos e Pontal do Paraná (Figura 1). Em termos de geomorfologia, a região é caracterizada por um conjunto de montanhas que compõem a Serra do Mar, por morros isolados de planície e insulares, por extensas planícies, por estuários (a baía de Guaratuba, ao sul, e o Complexo Estuarino de Paranaguá - CEP, ao norte) e pela plataforma continental. A região abriga uma ampla variedade de habitats naturais, incluindo costões rochosos, parcéis, marismas, planícies e canais de maré, restingas, manguezais, praias arenosas, além dos últimos remanescentes da Mata Atlântica brasileira (IPARDES, 1989; Lana et al., 2001).

O desenvolvimento urbano, agrícola e industrial paranaense tem se concentrado na região do primeiro planalto da Serra do Mar. Dessa maneira, os ecossistemas litorâneos encontram-se relativamente bem preservados, o que tem levado ao reconhecimento crescente da região pelo seu valor como patrimônio natural e à implementação de um amplo e restritivo arcabouço legal na tentativa de preservá-lo (Lana et al., 2001). Atualmente, mais de $80 \%$ do seu território é formado por Unidades de Conservação (Pierri et al., 2006). Mesmo assim, especialmente a partir das últimas quatro décadas, o litoral tem sofrido impactos antrópicos importantes, como a sobre-exploração dos estoques pesqueiros, o aumento do aporte de sedimento nos estuários devido a processos de desmatamento, a poluição dos corpos d'água pelo despejo de efluentes domésticos e em decorrência de atividades dos portos de Paranaguá e Antonina (Lana et al., 2001), além de alguns dos mais graves episódios de derrame de óleo ocorridos na costa brasileira (Noernberg et al., 2008).

Pontal do Paraná possui pouco mais de $200 \mathrm{~km}^{2}$ de área e está inserido na planície costeira de Paranaguá, entre o município de Matinhos (ao sul), o CEP (ao norte), a plataforma continental (a leste) e o município de Paranaguá (a oeste) (Figura 1). A população do município, em 2010, era de 20.919 habitantes, cerca de $8 \%$ da população do litoral (265.362 habitantes) (IBGE, 2010). A sua economia é fortemente baseada no turismo sazonal de sol e praia (Pierri, 2003). Segundo a SETU (2006), durante a temporada de verão Pontal do Paraná recebe, anualmente, cerca de 560.000 turistas (dados de 2005), o que aquece a economia e impulsiona atividades formais e informais. No resto do ano, a maioria dos trabalhadores volta à condição de desemprego ou subemprego, tentando sobreviver com o dinheiro conseguido na temporada e/ou a partir de oportunidades pontuais de trabalho. O município também abriga empresas de grande porte, inclusive multinacionais, especializadas na produção de componentes para plataformas petroleiras marinhas. Embora gerem uma quantidade significativa de empregos, o seu funcionamento é intermitente. Além disso, boa parte das vagas é ocupada por pessoas de fora, inclusive de outros estados (Pierri et al., 2006).

\section{A pesca no litoral paranaense e em Pontal do Paraná}

A pesca do litoral do Paraná é marcada por uma grande variedade de situações, desde uma atividade nitidamente artesanal ou mesmo de subsistência, realizada por produtores donos dos meios de produção e com equipamentos bastante simples, a empreendimentos empresariais, que produzem com força de trabalho contratada e que utilizam tecnologias de grande escala no contexto paranaense, mas de média ou pequena escala quando comparada a situações verificadas em outros estados das regiões sul e sudeste do Brasil (Andriguetto-Filho et al., 2006). 


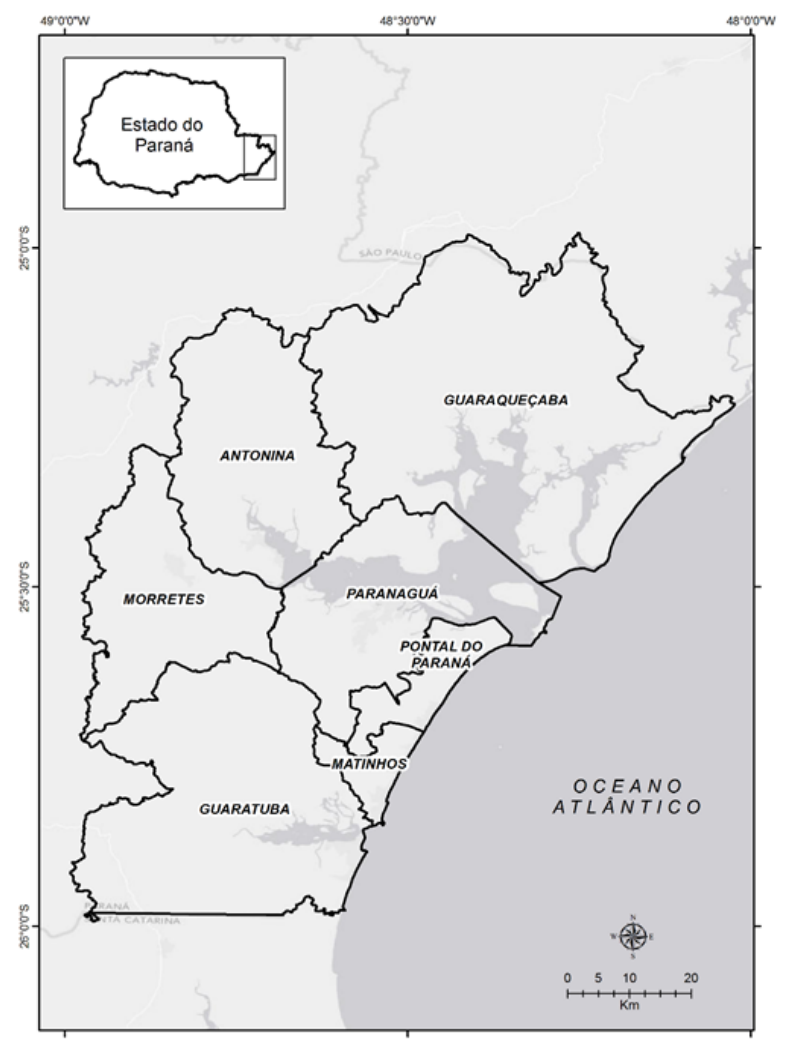

FIGURA 1 - Municípios do litoral do Paraná.

FONTE: Elaborado por Humberto Zontini Malheiros.

Embora a produção não tenha sido sistematicamente avaliada, a atividade parece ter importância apenas regional, com pouca expressão no cenário nacional (Andriguetto-Filho et al., 2006). Entretanto, é o principal meio de vida direto e indireto de uma parcela significativa da população do litoral. A região abriga mais de 70 vilas ou comunidades pesqueiras (Noernberg et al., 2008). Segundo Andriguetto-Filho et al. (2006), em 2003, havia um total de 4.277 pescadores profissionais registrados na SEAP - Secretaria Especial de Aquicultura e Pesca, órgão ligado ao Governo Federal.

Em 2008, cerca de 2\% da população de Pontal do Paraná, aproximadamente 400 pessoas, estavam registradas na Colônia de Pescadores do município, incluindo homens e mulheres que atuavam no beneficiamento e comercialização. A classe pesqueira está distribuída em 13 localidades, sendo sete na orla oceânica, cinco na orla de desembocadura do CEP, e uma na orla estuarina do município (Figura 2).

Em 2007, a frota motorizada do município era composta de 5 barcos de médio a grande porte (12 a 18 metros de comprimento) e 138 embarcações de pequeno porte (6 a 12 metros de comprimento), incluindo 123 canoas, 11 botes e 4 bateiras. A maior parte das canoas se concentrava na orla oceânica (98 embarcações), e os demais tipos de embarcação na região do canal artificial construído pelo DNOS - Departamento Nacional de Obras e Saneamento ("Canal do DNOS"), na desembocadura do CEP (Figura 2).

$\mathrm{O}$ arrasto de fundo para a captura de camarões é uma das técnicas de pesca mais difundidas durante a maior parte do ano, à exceção do período de defeso para o arrasto (março, abril e maio). Os principais alvos

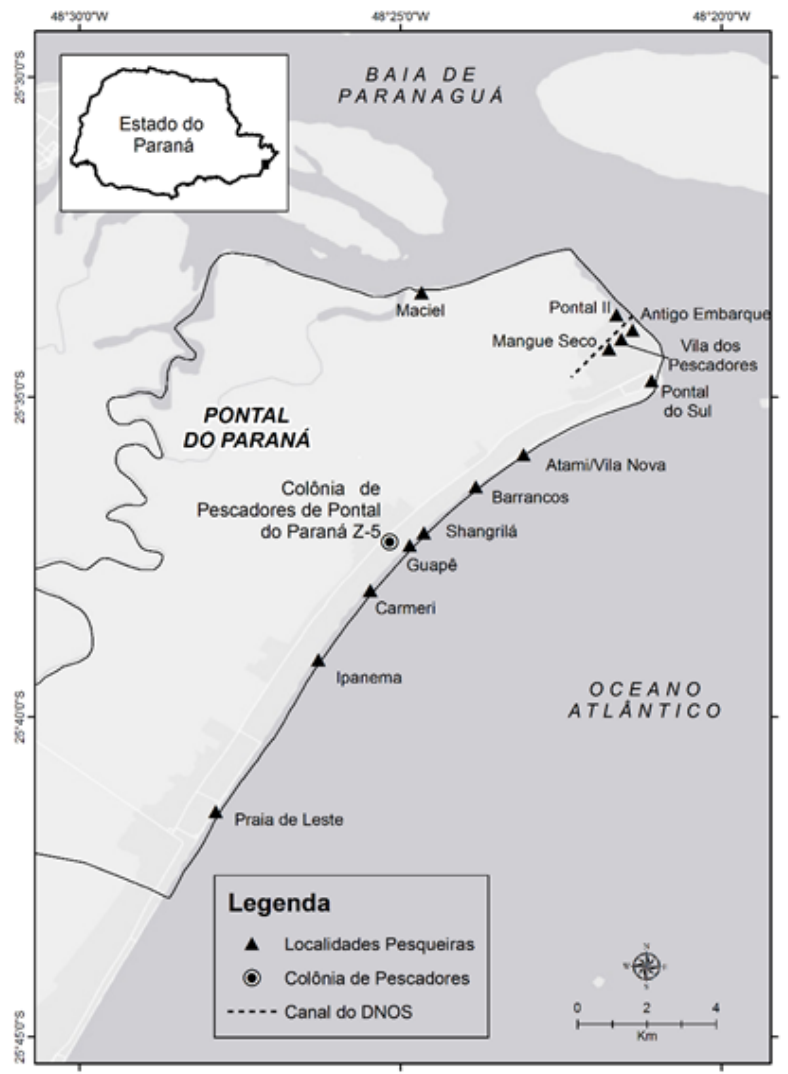

FIGURA 2 - Localidades pesqueiras de Pontal do Paraná.

FONTE: Elaborado por Humberto Zontini Malheiros 
são o camarão sete-barbas (Xiphopenaeus kroyeri) e o camarão-branco (Litopenaeus shimiti). Este último também é capturado pelas pescarias de caceio (rede de emalhe à deriva) e caracol (rede de emalhe tracionada pelo motor) com malhas de 5 ou $6 \mathrm{~cm}$ entre nós opostos. O caceio e o caracol são intensos nos meses de março, abril e maio (safra do camarão-branco). No restante do ano, tais práticas também capturam camarão-branco de maior tamanho (camarão-pistola) que, embora em quantidade reduzida, possui alto valor comercial.

Para a pesca de peixes, é utilizada uma grande variedade de práticas de emalhe, incluindo fundeio (redes fixas), cerco (rede disposta em círculo, cobrindo toda a coluna d'água), caracol, caceio (de superfície e de fundo) e arrastão de praia (lanços a partir da praia). Os principais alvos são a pescada membeca (Macrodon ancylodon), presente o ano todo; as pescadas branca (Cynoscion leiarchus), galheteira (Cynoscion microlepidotus) e amarela (Cynoscion acoupa), na primavera e no verão; a tainha (Mugil liza e Mugil platanus), em meados do outono e no início do inverno; o linguado (Paralichthys spp.), no final do outono e no inverno; a cavala (Scomberomorus brasiliensis e Scomberomorus cavalla), no inverno; a corvina (Micropogonias furnieri), na primavera; as salteiras (O. saliens), na primavera e no verão; e o robalo-flexa (Centropomus undecimalis), no final da primavera e no verão.

\section{Indicadores de resultados obtidos com a pesca em Pontal do Paraná}

\subsection{Eficiência econômica e equidade distributiva}

\subsubsection{Declínio da pesca de grande escala}

Da década de 1980 a meados da década de 1990, a região do Canal do DNOS foi o porto principal de mais de dez embarcações de médio a grande porte e com significativo aparato tecnológico (GPS, sondas, guinchos, rádio, etc.) voltadas para a pesca de peixes e/ ou de camarões. Estas estavam concentradas nas mãos de poucos armadores (entre uma e três por armador), alguns dos quais também dispunham de infraestrutura para o acondicionamento, transporte e beneficiamento (máquinas para a produção de gelo, câmaras frias, máquinas para o descasque de camarão, caminhão frigorífico, etc.).

Esse tipo de pesca experimentou forte diminuição, especialmente a partir da década de 1990. Segundo antigos armadores, a maioria desistiu da mesma em função da escassez dos recursos. Muitos migraram para outras atividades, especialmente aquelas ligadas ao turismo (aluguel de casas, estacionamentos, bares etc.). Dos que insistiram na pesca, quase todos experimentaram o declínio de suas unidades produtivas, até chegar à atual configuração de pequena produção diversificada, por vezes associada à comercialização de pescado e fornecimento de insumos.

O declínio da pesca de grandes embarcações contrasta com o bom desempenho da única unidade produtiva de grande escala remanescente no município. Administrado por uma família catarinense que chegou ao Paraná na década de 1960, o empreendimento é resultado da expansão de uma unidade produtiva de pequena escala, com capital construído por meio das atividades de pesca e comercialização (incluindo a intermediação) de pescado.

$\mathrm{Na}$ ocasião das entrevistas (2007), o empreendimento concentrava um capital superior a R\$ $1.500 .000,00$, composto por três embarcações arrasteiras de grande porte e uma peixaria com uma infraestrutura considerável (câmara fria, caminhão frigorífico, bancadas para a manipulação de pescado, etc.), através da qual comercializa sua produção e realiza a intermediação na venda de pescados. Os proprietários usufruem de um padrão de vida elevado, entre os mais altos do município. Estes possuem imóveis em Pontal do Paraná e em Guaratuba, além de vários veículos, alguns deles importados. De acordo com os proprietários, todo o patrimônio da família foi adquirido através das atividades de produção e comercialização de pescado.

\subsubsection{Crescimento, intensificação e diferenciação social na pesca de pequena escala}

Ao contrário da pesca de grande escala, a pesca artesanal ou de pequena escala de Pontal do Paraná tem se sustentado ao longo do tempo. Mais do que isso, a 
atividade experimenta um intenso processo de mudança e complexificação do qual derivam realidades e resultados socioeconômicos distintos.

Por um lado, a pequena pesca diversificada, composta principalmente pela frota de canoas que atua na plataforma continental imediata, mostra fortes sinais de eficiência econômica, crescimento e intensificação. As unidades produtivas mais eficientes conseguiram acumular, apenas com os rendimentos obtidos com a pesca, um capital superior a $R \$ 100.000,00$, distribuídos em embarcações (no máximo três), um conjunto considerável de equipamentos e, em alguns casos, infraestrutura para a comercialização. Em 2007, tais unidades proporcionavam um rendimento mensal médio superior a R \$3.500,00, cerca de dez salários mínimos na época² ${ }^{2}$ Seus proprietários possuem um bom padrão de vida e um patrimônio razoável. Alguns conseguiram adquirir, sobretudo com os rendimentos da pesca, mais de uma residência (geralmente em regiões bem valorizadas, próximas da praia) e um ou mais automóveis.

Por outro lado, os resultados não são satisfatórios para os proprietários de unidades menos equipadas, que se dedicam apenas ao arrasto de camarões ou ao emalhe de camarão-branco e pequenos peixes demersais (malhas de 5 e $6 \mathrm{~cm}$ entre nós opostos). Esses pescadores possuem um padrão de vida substancialmente mais simples do que os proprietários de unidades de pequena escala bem apetrechadas e, mais ainda, do que as famílias de armadores de grande escala. Em geral, são desprovidos de automóvel, residem em regiões pouco valorizadas ou em situação fundiária "irregular" (sem propriedade privada nem direito de uso legalizado), e condições relativamente precárias de habitação. Apesar dos rendimentos relativamente expressivos obtidos em períodos como a temporada de verão e a safra do camarão-branco, tais unidades mostram fortes sinais de vulnerabilidade e ineficiência econômica. As condições de acumulação são limitadas, e o capital pesqueiro dificilmente ultrapassa a casa dos $\mathrm{R} \$ 30.000,00$, correspondentes a uma embarcação motorizada e um conjunto reduzido de apetrechos. Nos piores meses, a renda mensal com a pesca pode ser inferior a um salário mínimo. Com frequência, seus proprietários se deparam com dificuldades para repor os instrumentos de produção e prover as necessidades básicas dos seus familiares. A situação é mais crítica no inverno e em meados da primavera, quando a alta incidência de ventos dificulta a saída para o mar e seus principais recursos alvo são escassos ou com pouco valor comercial. Nessas circunstâncias, lidam constantemente com a necessidade de vender seus instrumentos de trabalho e/ou vender sua força de trabalho a proprietários de unidades produtivas mais equipadas. Outra alternativa é o abandono da pesca para buscar outras fontes de renda. Entretanto, estas nem sempre se apresentam no momento certo e na medida suficiente.

Os quinhoeiros, indivíduos que trabalham para proprietários de embarcações e instrumentos em troca de parte da produção obtida, apresentam características socioeconômicas semelhantes aos pescadores pouco apetrechados. Geralmente possuem padrão de vida simples, com pouco ou nenhum patrimônio. Para aqueles que trabalham em unidades equipadas e pujantes, os rendimentos mensais costumam ser superiores a $\mathrm{R} \$$ $1.000,00$, o que é considerado satisfatório no contexto do município. Já nas unidades pouco apetrechadas, os períodos de pesca ruim costumam render menos de um salário mínimo mensal, o que resulta em dificuldades para o sustento e motiva o abandono da posição em busca de outras oportunidades de trabalho.

\subsection{Evidências de sobre-exploração e de usos destrutivos}

Muitos recursos capturados pela pesca do município integram as listas nacionais de espécies sobre-exploradas ou ameaçadas de sobre-exploração, como corvina, pescada membeca, camarão-branco, camarão sete-barbas, e tainha (MMA, 2004). Tal quadro é corroborado pela percepção dos pescadores locais, que apontam uma forte tendência de queda nos rendimentos das capturas, tanto de peixes quanto de camarões.

\footnotetext{
${ }^{2}$ Os rendimentos referidos correspondem àqueles obtidos com a venda do pescado produzido, descontando-se apenas os gastos com combustível e pagamento da tripulação.
} 
Convém esclarecer que a condição dos recursos e a integridade dos ecossistemas que sustentam a pesca de Pontal do Paraná não dependem apenas dos usos praticados pelos pescadores locais. As áreas de pesca utilizadas pelos pescadores locais são comumente acessadas por pescadores de outros municípios e estados. Além disso, os recursos são móveis e os estoques se distribuem para além do alcance da frota local. Assim, o estado da base de recursos e a integridade dos ecossistemas que sustentam a pesca de Pontal do Paraná dependem também dos padrões de uso praticados por pescadores de outros municípios, de outros estados e até mesmo de outros países. A situação é ainda mais complexa devido à influência de outros fatores antrópicos, como a poluição urbana, portuária e industrial.

Não existem dados de desembarque e de esforço de pesca, tampouco estatísticas ou estudos que possam subsidiar avaliações conclusivas das consequências da pesca de Pontal do Paraná na base de recursos e nos ecossistemas. No entanto, verificam-se usos potencialmente destrutivos e incongruentes com os imperativos de conservação.

A pequena pesca do município tem experimentado, especialmente nas últimas duas décadas, um forte processo de intensificação. Uma mudança importante foi a substituição das canoas de madeira pelas de fibra, principalmente a partir do final da década de 1990. As últimas, que já predominam em todos os portos pesqueiros visitados, possuem maior capacidade de carga, além de serem mais leves e maiores, o que proporciona melhorias em várias etapas do processo de trabalho (navegação, colocação e retirada das canoas no mar, manuseio das redes, etc.).

Na pesca de peixes, os pescadores são unânimes em reportar um significativo aumento na quantidade e nas dimensões das redes de emalhe. Na pesca do linguado, por exemplo, as unidades mais pujantes utilizam cerca de 5.000 metros de redes de fundeio em uma operação de pesca, mais do que o dobro do utilizado no final da década de 1990. Já as "redes altas" para o lanço de peixes como tainhas e cavalas, bastante difundidas a partir de meados da década de 2000, chegam a $30 \mathrm{~m}$ de altura e $1.000 \mathrm{~m}$ de comprimento.

$\mathrm{Na}$ pesca de arrasto para a captura de camarões, principalmente a partir de meados da década de 2000 , chama a atenção o uso de tangones em canoas, o que permite a operação de duas redes simultaneamente. Muitas embarcações também possuem guinchos, o que diminui o esforço físico e o tempo de despesca, permitindo a execução de um número maior de lanços. Vale frisar que o arrasto tem sido reconhecido pela comunidade científica, por ONGs ambientalistas, por gestores e pelos próprios usuários como uma das práticas mais incongruentes com as características dos recursos e ecossistemas do litoral paranaense (Brandini, 2013), principalmente devido às evidências de efeitos negativos sobre várias espécies de peixes demersais capturados como fauna acompanhante (Chaves et al., 2003; Bernardo et al.,2011).

Embora ainda não avaliados por pesquisas científicas, os efeitos negativos do uso da malha de $5 \mathrm{~cm}$ estão fortemente presentes na percepção dos usuários locais. Para estes, o uso intenso do equipamento é responsável pela morte de grande quantidade de juvenis de peixes. A situação piora porque no intuito de capturar pequenos peixes demersais (especialmente a pescada membeca) muitos utilizam o equipamento fora do período permitido pela legislação (março, abril e maio).

\section{As relações econômicas e os resultados obtidos com a pesca}

\subsection{A Lei do Valor}

A pesca profissional em Pontal do Paraná é realizada principalmente como atividade mercantil. Na economia mercantil, além do valor de uso ou capacidade de satisfazer as necessidades da sociedade, as mercadorias possuem um valor de troca, fator quantitativo que permite comparar as diferentes mercadorias e organizar as relações de intercâmbio e comercialização. Para estabelecer o valor de troca é necessário um padrão de medida comum a todas as mercadorias e que seja divisível em unidades homogêneas. Segundo a economia clássica e a economia marxista, esse padrão de medida é o trabalho investido para a sua produção, o qual é medido em termos de tempo de trabalho (Foladori \& Melazzi, 2009).

Em qualquer atividade econômica, as unidades de produção possuem ritmos e condições diferenciados. 
Sendo assim, o mercado tende a reconhecer o tempo médio que, em determinada sociedade e momento, é necessário para produzir certa mercadoria. Esse tempo expressa as condições médias de produção e é denominado de Tempo de Trabalho Socialmente Necessário (TTSN). Nesse processo, as unidades que produzem em um tempo menor que o TTSN se apropriam da diferença entre o valor individual de seu produto e o valor médio de mercado, o que lhes garante um ganho extra. Por outro lado, as unidades com piores condições de produção e que produzem em um tempo maior que o TTSN recebem apenas o valor médio, e o mercado transfere o que elas perdem (a diferença entre o valor individual e o médio) para as unidades mais produtivas (Marx, 1987) ${ }^{3}$. Essa dinâmica, conhecida como lei do valor, representa o principal regulador do funcionamento da economia mercantil, e é essencial para o entendimento dos processos econômicos e sociais que determinam os resultados obtidos com a pesca em Pontal do Paraná.

Em primeiro lugar, ao pressionar os concorrentes para melhorar sua produtividade, a lei do valor determina o ritmo de desenvolvimento das forças produtivas materiais, que são todos os elementos que intervêm na produção, sendo o mais dinâmico a tecnologia aplicada. No caso da pesca, trata-se das inovações técnicas que melhoram a navegação, aumentam o rendimento das capturas, e melhoram o acondicionamento, processamento e transporte dos produtos. A lei do valor determina também a forma desse desenvolvimento, de maneira que o objetivo do lucro privado - e não as necessidades sociais - condiciona o tipo de inovações geradas. Isto se expressa, por exemplo, nos custos ambientais e sociais que muitas vezes essas inovações acarretam. Em terceiro lugar, a lei do valor determina o desenvolvimento da divisão social do trabalho, isto é, o incremento da especialização em novos ramos e produtos, que é uma estratégia defensivo-ofensiva dos produtores no marco da concorrência. No caso da pesca isto se expressa na diversificação das espécies alvo e dos produtos e subprodutos oferecidos no mercado. Em quarto lugar, a lei do valor determina o processo de diferenciação social entre os produtores do mesmo produto. Enquanto aqueles com melhores condições de produção conseguem manter ou ampliar suas unidades produtivas e ter um bom padrão de vida, os pescadores menos competitivos vivem em situação de pobreza e vulnerabilidade e muitas vezes são obrigados a vender seus instrumentos e/ou sua força de trabalho para proprietários de outras unidades produtivas, ou, ainda, buscar alternativas de trabalho fora da pesca. Assim, a diferenciação social consiste na tendência ao enriquecimento de poucos e ao relativo empobrecimento da maioria (Foladori \& Melazzi, 2009). Trata-se de uma dinâmica que opera em distintos níveis. Além da concorrência entre os pescadores da mesma região, existe a concorrência com produtores de outras regiões, já que o pescado local concorre com produtos de origem externa, inclusive internacional. Por outro lado, os produtores da pesca extrativa concorrem também com os que produzem pescado mediante a aquicultura, e todos eles com os produtores dos demais alimentos e mesmo dos demais setores produtivos.

\subsection{Condições para intensificação e diversificação do esforço de pesca}

As unidades produtivas de pequena escala bem sucedidas são conhecidas localmente pela constância das atividades. Estas raramente ficam ociosas e realizam operações de pesca quase sempre que há condição de mar. O trabalho também é constante em terra (limpeza, manutenção e confecção de redes, manutenção de embarcações, etc.).

\footnotetext{
${ }^{3}$ O TTSN para produzir uma mercadoria, ou o seu valor de troca, não é conhecido ou visualizado pelos produtores. Ele corresponde a uma média social estabelecida a partir de sucessivas aproximações, e que muda constantemente na medida em que se desenvolve a produtividade. Convém ainda diferenciar o conceito de valor de troca do conceito ou termo preço. Os preços correspondem à aparência ou forma que o valor de troca assume no mercado. Suas variações podem estar ligadas a dois tipos principais de fatores. O primeiro deles está ligado a mudanças no próprio valor de troca, como nos casos de diminuição do valor devido ao aumento da produtividade social do trabalho. O segundo fator está relacionado às flutuações na oferta e na demanda, que determinam as variações que ocorrem em torno do valor de troca. Em situações de demanda maior em relação à oferta, os preços tendem a aumentar significativamente. Já quando a oferta do produto é maior em relação à demanda, os preços pagos pelo produto tendem a diminuir (Marx, 1987).
} 
$\mathrm{O}$ aumento da produtividade individual do trabalho, fundamental para um bom posicionamento nas relações de concorrência, também é uma característica marcante dessas unidades. Este ocorre principalmente pela introdução das inovações técnicas descritas anteriormente. Em algumas unidades, visando aumentar a produtividade, também ocorre divisão do trabalho: enquanto uma parte da força de trabalho atua nas pescarias, outra parte se encarrega do trabalho em terra (limpeza, processamento, comercialização, etc.).

Os empreendimentos com melhor desempenho econômico também possuem melhores condições para a diversificação das práticas de pesca, o que contribui para o aumento da resiliência e redução da vulnerabilidade às mudanças, perturbações e incertezas que marcam a pequena pesca. Entre algumas das vantagens, estão:

- Melhor resposta à sazonalidade na disponibilidade de pescado, permitindo o direcionamento do esforço de pesca para as "safras" ou períodos com maior disponibilidade de determinados recursos;

- Melhor resposta às pequenas flutuações no rendimento das pescarias. Durante o inverno, por exemplo, uma unidade de produção dedicada à captura do linguado pode voltar-se para a captura de tainhas ou de cavalas, caso a pesca do linguado esteja ruim ou as informações disponíveis indiquem a presença de cardumes desses recursos;

- Melhor resposta às flutuações nos preços de pescado, permitindo o direcionamento do esforço para os recursos mais compensatórios e reduzindo a vulnerabilidade à desvalorização causada pelo aumento da produtividade social do trabalho ou pelas oscilações na oferta e demanda;

- Melhor condição de adaptação à legislação, aumentando o leque de práticas possíveis e reduzindo as chances de comprometimento das atividades em função de eventuais restrições.

Contudo, diversificar a produção requer um capital relativamente alto. Um conjunto de equipamentos razoável, composto de equipamento para arrasto de camarões, redes para caceio de camarão-branco, redes de fundeio para captura de linguado, robalo-flecha e pescadas, e redes de cerco e caceio de peixes como tainhas, corvinas e cavalas, pode custar algo em torno de $\mathrm{R} \$ 50.000,00$. A estratégia também requer equipes de trabalho dedicadas, constantes e com habilidade para realizar a manutenção dos equipamentos e atuar satisfatoriamente em diferentes práticas de pesca, o que, segundo os pescadores, é cada vez mais difícil.

As unidades menos capitalizadas e com força de trabalho limitada geralmente se dedicam ao arrasto de fundo e/ou ao caceio e caracol para a captura de camarão-branco e pequenos peixes demersais (com malhas 5 e $6 \mathrm{~cm}$ ). Além de demandarem investimentos baixos e incidirem sobre recursos presentes durante boa parte do ano (especialmente o camarão sete-barbas e a pescada membeca), tais práticas demandam pouca força de trabalho, podendo até ser exercidas individualmente.

\subsection{A propriedade dos instrumentos de produção}

As unidades de produção mercantil simples, que funcionam exclusivamente com a força de trabalho do produtor e de sua unidade familiar ou domiciliar, são raras na pesca de Pontal do Paraná. Geralmente, a expansão das unidades produtivas ou o desfalque na força de trabalho familiar fazem com que a necessidade de força de trabalho ultrapasse a capacidade do pescador e de sua família ou domicílio. Nesses casos, os proprietários de meios de produção atuam como pequenos capitalistas ou armadores de pesca, recorrendo à força de trabalho dos quinhoeiros.

Na maioria das vezes, os proprietários das unidades produtivas participam do processo produtivo. Em outros casos, ocorre o distanciamento, esporádico ou definitivo, dos proprietários para com o trabalho direto na pesca, e estes confiam seus instrumentos aos quinhoeiros. Existem também os pequenos armadores externos às comunidades de pescadores. Estes normalmente são proprietários de residências de veraneio ou comerciantes locais que investem na pequena pesca, adquirindo uma ou mais embarcações de pequeno porte e um conjunto considerável de equipamentos, os quais são operados por quinhoeiros locais.

A divisão dos rendimentos ocorre pelo sistema das partes ou quinhão. Depois de descontadas as despesas (normalmente com o combustível e, eventualmente, com 
o gelo), metade dos rendimentos vai para o proprietário da embarcação e a outra metade é dividida entre os pescadores que participam da atividade de captura. Se o proprietário participa da pesca, recebe, além da parte que lhe é destinada por sua condição, a parte correspondente ao seu trabalho. Por exemplo, se o proprietário e um quinhoeiro executam a pescaria, o proprietário fica com $75 \%$ do rendimento e o quinhoeiro com $25 \%$.

Esse sistema resulta na apropriação de uma parcela maior da riqueza por parte dos que detém a propriedade privada dos meios de produção, contribuindo para ampliar o processo de diferenciação social entre os produtores envolvidos na pesca. Em Pontal do Paraná, isso é evidente quando comparamos a situação econômica dos proprietários de unidades de produção bem equipadas com a situação dos quinhoeiros. No caso dos quinhoeiros, a sua pobreza relativa, somada à vontade de se tornar um produtor independente, contribui para que quase todos almejem o rompimento da subordinação ao patrão de pesca e a constituição de unidades produtivas próprias. E esse não é um feito raro na pesca pontalense. É relativamente comum que bons rendimentos na pesca, ou mesmo outras formas de acesso a capital, tais como linhas de crédito, outras fontes de renda ou mesmo ajuda de parentes, propiciem ao pescador a formação de sua própria unidade produtiva. As novas unidades, no entanto, geralmente ingressam na pesca tendo que competir com outras mais capitalizadas, mais bem equipadas e com melhores condições de comercialização da produção.

\subsection{A comercialização da produção}

Com o aumento da população permanente e da presença de turistas no município, principalmente a partir da década de 1980, melhoraram significativamente as condições para a venda direta de pescado ao consumidor final.

$\mathrm{Na}$ orla oceânica do município, a maioria das unidades produtivas dispõe de bancas ou mercados comunitários instalados na praia para a venda direta ao consumidor. Em geral, as instalações consistem em uma estrutura abrigada com bancadas, balanças para a pesagem dos produtos, pias, água potável e energia elétrica. Os produtos normalmente são acondicionados em recipientes com gelo.

A venda direta também é feita em dezenas de peixarias espalhadas ao longo da orla ou do perímetro urbano. Estas podem ser de pescadores, de armadores ou de pequenos comerciantes que se dedicam exclusivamente à venda de pescado. A grande maioria das peixarias é de pequeno porte e conta apenas com um ou dois freezers, balcão frigorífico, equipamento de pesagem e bancadas para manipulação e beneficiamento de pescado. No entanto, alguns estabelecimentos contam com infraestrutura considerável, incluindo câmara fria, máquinas para o descasque de camarões e fábrica de gelo.

Nos períodos em que a demanda por pescado é abundante no município, como nas férias de verão e feriados prolongados, a produção dos pescadores locais não é suficiente para supri-la. Nas bancas, mercados comunitários e pequenas peixarias pertencentes a pescadores, os produtos se esgotam rapidamente. Já as peixarias de maior porte, vendem principalmente produto oriundo de outros locais. Os produtos podem ser buscados pelos proprietários destes estabelecimentos ou trazidos por intermediários e podem ser oriundos de outros municípios do litoral paranaense, da frota industrial de estados vizinhos (principalmente Santa Catarina e São Paulo), da carcinicultura do Nordeste e até mesmo de outros países, como o salmão chileno e o peixe-panga asiático.

Outra forma comum de comercialização é a venda para "clientes especiais", geralmente proprietários de residências de veraneio que habitualmente adquirem produtos de determinado pescador. Tanto na orla oceânica quanto na região do Canal do DNOS, alguns pescadores também oferecem o produto "de casa em casa", geralmente se locomovendo de bicicleta.

A venda de pescado para restaurantes também é frequente entre pescadores do município. No entanto, de acordo com proprietários desse tipo de empreendimento, os preços altos, a pouca variedade de produtos e das formas de apresentação e a oferta pequena e irregular dos produtos oriundos da pesca local, tornam mais compensatória a compra de produtos provenientes de outras regiões.

Apesar das melhorias das condições para a venda da produção diretamente ao consumidor final, principalmente nos períodos de maior presença de turistas, na 
maior parte do ano os pescadores ainda dependem dos intermediários para escoar a produção, dividindo com estes uma parte do valor de sua mercadoria. Os intermediários geralmente são locais ou de municípios vizinhos (principalmente Guaratuba, Matinhos e Paranaguá) e revendem o produto em suas peixarias ou para outros estabelecimentos do litoral e de Curitiba.

Os preços com que os produtos locais são oferecidos ao consumidor final são significativamente maiores que os preços pagos pelos intermediários ao pescador. Algumas transações de venda acompanhadas pela pesquisa revelaram preços de venda ao consumidor final de 50 a $500 \%$ maiores do que os pagos aos pescadores. Para alguns, a dependência em relação aos intermediários é vista como importante condicionante dos maus resultados econômicos. Essa percepção é mais difundida entre os pescadores da região do Canal do DNOS, onde não existem bancas ou mercados comunitários e a possibilidade de venda direta ao consumidor é muito limitada. Vale lembrar que nesse local está o maior empreendimento pesqueiro da região, cujo bom desempenho é, em grande parte, explicado pela apropriação durante mais de três décadas de parte da riqueza produzida pelos pescadores locais. Além da infraestrutura e do conhecimento acerca do funcionamento do mercado, que permitem investir em estratégias eficientes de intermediação, o empreendimento possui grande tradição na venda para o consumidor final. Isso amplia os ganhos desta empresa sobre a produção dos pescadores de pequena escala, bem como proporciona vendas bastante compensatórias da própria produção.

A comercialização também é difícil para as unidades pouco diversificadas e que exploram recursos como camarão sete-barbas e pescada membeca, cujos preços sofrem grandes variações e caem significativamente quando a captura pela frota local é abundante o suficiente para saturar as unidades de comercialização. No caso das unidades diversificadas, o esforço pode ser dirigido a pescarias que estejam mais rentáveis. Vale notar que alguns recursos, como o camarão-branco, o linguado e o robalo-flecha, não sofrem quedas expressivas nos preços. Estes são produtos considerados nobres, altamente demandados e com oferta reduzida, principalmente quando frescos.

\subsection{As relações econômicas e os maus resultados ecológicos}

A literatura acerca da gestão de recursos comuns tem enfatizado que o engajamento em estratégias para a conservação tende a ser difícil quando as restrições necessárias para a sustentabilidade ecológica colidem com os imperativos de sobrevivência e de satisfação das necessidades básicas dos usuários dos recursos (Ostrom, 1990; Singh, 2003). As informações obtidas por essa pesquisa evidenciam que essa é uma dificuldade presente na pesca pontalense. Entretanto, o estudo de elementos referentes à organização social da produção proporciona uma visão mais profunda do problema.

Em um contexto de produção direcionada ao mercado, para garantir uma boa posição nas relações de concorrência mediadas pela lei do valor, os pescadores devem manter níveis satisfatórios de produtividade, produzindo a maior quantidade de pescado possível no tempo dedicado às capturas. Mais que garantir renda suficiente para o sustento do pescador e de sua família, ou de simplesmente repor os instrumentos de produção, isso inclui a necessidade de acumular capital a ponto de melhorar suas condições de produção e comercialização, assim como constituir um fundo de reserva que diminua a sua vulnerabilidade frente aos imprevistos inerentes à atividade, como períodos de rendimento excepcionalmente baixos, queda nos preços, extravio ou dano de equipamentos, problemas de saúde, etc. Essa dinâmica é fundamental na configuração dos padrões de intensificação e exploração acelerada dos recursos pesqueiros. Vale frisar que, além das mudanças nos equipamentos e intensificação no ritmo de trabalho, a busca por maior produtividade também estimula práticas potencialmente destrutivas. Por exemplo, muitos pescadores buscam locais que costumam proporcionar maior rendimento, mas que possuem um papel chave para o funcionamento dos ecossistemas e renovação dos recursos, tais como regiões próximas à costa e proximidades de canais, ilhas, parcéis e costões rochosos.

$\mathrm{O}$ aumento da demanda pelo pescado produzido pelos pescadores do município também é fundamental para configurar maus resultados ecológicos. Essa dinâmica tem feito com que recursos que costumavam 
ser rejeitados, doados ou utilizados na alimentação da família dos pescadores adquiram valor comercial. Um bom exemplo são os pequenos peixes demersais antes capturados principalmente como fauna acompanhante do arrasto e que, com o aumento da demanda, se tornaram alvo de pescarias de emalhe com malhas de 5 e $6 \mathrm{~cm}$, consideradas altamente impactantes.

A acessibilidade econômica dos instrumentos de produção também é relevante. Os instrumentos necessários para algumas das práticas mais impactantes (arrasto de fundo, caceio e o caracol com malha $5 \mathrm{~cm}$ ) são os mais acessíveis e capturam recursos disponíveis o ano todo, o que contribui para que sejam utilizados pela maioria dos usuários. No caso do arrasto de fundo e do caracol, a facilidade para a pesca individual, aumentando os ganhos e minimizando o problema da falta de força de trabalho, também representa um importante atrativo.

\section{As instituições para o manejo dos recursos}

Como já dito, o quadro de insustentabilidade dos recursos pesqueiros não depende apenas das atitudes dos pescadores de Pontal do Paraná ou do litoral paranaense. Contudo, não se pode negar que as dificuldades para o manejo da pesca na região, cada vez mais intensificada e ecologicamente destrutiva, contribuem para essa situação.

Em Pontal do Paraná, as condições para a construção de estratégias de cooperação para o uso sustentável dos recursos são desfavoráveis no que se refere a alguns dos fatores destacados pela literatura acerca do uso e apropriação de recursos comuns, inclusive recursos pesqueiros (Ostrom, 1990; Oakerson, 1992; Berkes et al., 2001; Singh, 2003).

Existem condições limitadas para que os pescadores compreendam as consequências de suas ações no sistema de recursos que utilizam. Apesar das evidências científicas e da percepção dos pescadores a respeito dos usos potencialmente destrutivos, da queda nos rendimentos das capturas e da sobre-exploração de muitos recursos, o conhecimento disponível está longe de demonstrar - de maneira precisa e taxativa - quais os efeitos ecológicos das diferentes modalidades e intensidades de uso praticadas pelos pescadores do município.
É difícil definir quais práticas devem ser evitadas e quais devem ser estimuladas, ou dimensionar os efeitos de determinadas medidas de manejo nos ecossistemas e recursos locais.

A falta de participação e representatividade dos usuários locais, a multiplicidade de vias pelas quais a legislação pesqueira tem sido criada e os problemas de conexão entre escalas de gestão (estadual, regional e nacional) resultam em um quadro normativo complicado, contraditório, e inadequado à realidade local.

A fiscalização das normas também é deficiente. As condições materiais e de recursos humanos para o policiamento são bastante reduzidas, e o trabalho ocorre principalmente por meio do atendimento a denúncias e operações pontuais. A fiscalização costuma ser um pouco mais intensa no período de defeso do arrasto e durante a temporada de verão. Além disso, o rigor é maior no caso das regras para o arrasto de camarões, principalmente o licenciamento, o defeso e os limites espaciais. Algumas regras da pesca de emalhe, como aquelas relacionadas à altura e comprimento das redes, raramente são fiscalizadas.

Se, por um lado, as dificuldades de fiscalização comprometem a efetividade das medidas de conservação dos recursos, por outro, minimizam os efeitos negativos da legislação na economia pesqueira do município. Se fosse aplicada com rigor, a legislação inviabilizaria ou comprometeria significativamente quase todas as práticas de pesca utilizadas pelos pescadores locais.

Em 2007, o uso de redes de emalhe com altura maior que a metade da profundidade do local de pesca foi proibido em águas sob jurisdição nacional (IBAMA, 2007), o que tornou proibidas práticas como o cerco e o arrastão de praia. A nova legislação estabelecida para o emalhe nas regiões Sudeste e Sul (MMA \& MPA, 2012) é ainda mais impactante, pelo menos potencialmente. Ao estabelecer a altura máxima de quatro metros para as redes de emalhe, esta pode comprometer seriamente $o$ desempenho econômico da pesca de caceio de superfície, além de tornar o cerco e o arrastão de praia praticamente inviáveis. Ao permitir apenas o uso de redes com malhas entre 7 e 14 cm entre nós opostos, a legislação inviabiliza a captura de recursos importantes, como linguado, robalo-flecha, corvina e cação. A pesca de caceio com malhas de 5 e $6 \mathrm{~cm}$ direcionada ao camarão-branco e à 
pescada membeca também fica proibida pela nova legislação. Vale lembrar que o caracol, amplamente utilizado para a captura desses recursos, já era proibido estado do Paraná (IBAMA, 2003).

Em 2008, foi estabelecida a proibição de qualquer modalidade de pesca entre 15 de março e 15 de agosto nas áreas de desembocaduras estuarino-lagunares das regiões Sudeste e Sul (IBAMA, 2008). Isso inviabiliza a pesca da tainha em pontos de arrastão de praia de Pontal do Sul, colocando em risco um dos sistemas de pesca mais tradicionais do litoral paranaense.

No que se refere à legislação criada pelos órgãos estaduais, convém citar a implantação do defeso dos robalos nos meses de novembro e dezembro (SEMA, 2009), considerados os mais rentáveis para a pesca do robalo-flecha. Já a proibição da fixação de redes a menos de meia milha náutica da costa (IAP, 2009) inviabiliza o fundeio de redes tipo feiticeira nas praias, pescaria importante para o sustento de muitos quinhoeiros e pescadores desprovidos de embarcação.

A percepção de injustiça em relação ao excesso de restrições é motivo de conflitos entre os usuários locais e os gestores. Para os pescadores, as medidas lhes atribuem parcela exagerada da responsabilidade sobre o estado dos estoques pesqueiros, assim como dos custos decorrentes de sua recuperação ou conservação. Muitos também questionam a efetividade das normas tendo em vista a existência de outros fatores tão ou mais impactantes que a pesca de pequena escala, como a pesca industrial e os impactos crescentes da ocupação urbana desordenada e das atividades portuárias e industriais. Ainda segundo os usuários locais, mesmo que em médio ou longo prazo tais normas possam promover a recuperação dos estoques e, consequentemente, o aumento nos rendimentos, em curto prazo, a sua aplicação certamente traria consequências indesejadas, como vulnerabilidade socioeconômica e a degradação da cultura pesqueira da região. A indignação aumenta porque boa parte dos petrechos utilizados nessas práticas foi adquirida através de financiamentos incentivados pelo Ministério da Pesca e Aquicultura por meio da abertura e ampla divulgação das linhas de crédito.

\section{Novos caminhos para a gestão pesqueira local}

\subsection{Construção de novas relações sociais de produção}

A pesca de Pontal do Paraná está fundada na propriedade privada individual dos instrumentos de produção, em relações sociais desiguais entre os proprietários e os quinhoeiros, e na competição desigual entre unidades produtivas. Para os proprietários, interessa acumular capital e melhorar suas condições de produção, o que inclui não apenas investir em equipamentos, mas também recrutar pescadores despossuídos de meios de produção e constituir equipes de trabalho eficientes e constantes. Os quinhoeiros, por sua vez, almejam se tornar independentes, possuir seus próprios instrumentos de produção, expandir cada vez mais seu capital e passar à condição de "patrão de pesca".

A distribuição desigual da riqueza gerada, a diferenciação social e a marginalização de segmentos da classe pesqueira são elementos intrínsecos ao modo de produção mercantil capitalista. Enquanto vigorarem tais relações de produção, existirão produtores em desvantagem, com unidades pouco equipadas, disponibilidade limitada de força de trabalho e especializadas em poucas práticas de pesca. Da mesma forma, sempre haverá os quinhoeiros subordinados ao patrão de pesca.

A busca de equidade e o combate à pobreza e à marginalização passam, necessariamente, por mudanças nas relações de produção que regem a pesca do município. Inicialmente, isso pode ser feito através do estímulo à constituição de unidades de produção fundadas no sistema de parcerias ou, ainda, com propriedade coletiva dos meios de produção. A meta central seria equalizar as condições para diversificação e intensificação da produção, assim como a posição dos pescadores em relação à propriedade dos meios de produção. Ao invés de duas ou mais unidades produtivas limitadas em termos de instrumentos e força de trabalho, cujos parcos e instáveis rendimentos são divididos de maneira desigual entre os proprietários e quinhoeiros, seria preferível constituir uma única unidade, mais equitativa (com a propriedade dos instrumentos de produção difundida 
entre os trabalhadores e com formas igualitárias de divisão dos rendimentos econômicos obtidos) e mais eficiente economicamente (mais equipada, com maior força de trabalho e, portanto, com melhores condições de diversificação e intensificação).

\subsection{Melhoria das condições de comercialização}

A venda de pescado por meio de cooperativas pode contribuir para a melhoria das condições de comercialização. Todavia, a implantação de cooperativas não pode ser tida como uma panaceia para a resolução dos problemas ligados à comercialização do pescado. Na década de 1980, muitos pescadores de Pontal do Paraná participaram da COOPESPAR - Cooperativa dos Pescadores Artesanais do Litoral Paranaense. A cooperativa, entretanto, enfrentou uma série de problemas, que culminaram com a sua liquidação em meados da década de 1990.

A organização foi criada "de cima para baixo", a partir de aspectos organizacionais e de infraestrutura projetados de antemão, sem a participação dos pescadores, o que contribuiu para que o empreendimento fosse inadequado à realidade local.

A eficiência econômica era comprometida pelos elevados custos fixos, principalmente os custos de manutenção dos equipamentos (que eram caríssimos e estragavam com facilidade) e os pesados encargos sociais e fiscais. Algumas características das pescarias e dos recursos explorados pioraram a situação. Os altos custos de produção, a sazonalidade da disponibilidade dos recursos, a produção relativamente pequena e a inconstância na produção impediam a regularização da oferta e a estabilidade dos preços. Isso tornava a organização pouco competitiva frente às grandes empresas de outros estados, que capturavam grandes quantidades e podiam ofertar pescado com mais constância e a preços mais atrativos. Desse modo, não era possível pagar um bom preço pelo pescado dos associados, e muitos acabavam vendendo seus produtos a preços maiores para atravessadores ou para o consumidor final.
As dificuldades para a organização e cooperação sempre foram fortes obstáculos. Não houve orientação e preparo consistente das comunidades beneficiárias, e a baixa escolaridade dos envolvidos dificultou a assimilação de conhecimento sobre a administração cooperativista. Era difícil encontrar representantes das diferentes comunidades, e a frequência dos pescadores nas reuniões era baixa. Para piorar, havia rivalidades entre pessoas, entre comunidades, e entre grupos de pescadores que utilizavam práticas potencialmente conflitantes. Como consequência, os pescadores não conseguiram se apropriar efetivamente da gestão da organização, que, na prática, ficou por conta de técnicos do governo. ${ }^{4}$

A experiência da COOPESPAR, assim como outras informações obtidas sobre a comercialização do pescado local, traz lições interessantes. Em primeiro lugar, entende-se que as estratégias de comercialização devem ser construídas de forma localizada, envolvendo grupos pequenos de pescadores em empreendimentos simples, que demandem pouco esforço adicional e baixos níveis de cooperação e coordenação. Paralelamente, devem ser realizadas estratégias consistentes de capacitação dos produtores, as quais devem envolver aspectos técnicos, administrativos, sanitários e organizacionais. $\mathrm{O}$ trabalho poderia começar pela implantação de bancas e mercados comunitários nos locais onde esses ainda não existem, assim como pela realização de melhorias logísticas e organizacionais nas estruturas existentes. Na medida em que os resultados positivos da cooperação forem percebidos, e na medida em que os pescadores se tornem mais capacitados, poderiam ser propostas estratégias mais complexas, envolvendo, por exemplo, uma maior infraestrutura e grupos maiores de pescadores.

Outro ponto fundamental é que a pesca local enfrenta dificuldades ao concorrer com a pesca industrial em quesitos como valor dos produtos, quantidade e constância no fornecimento. Assim, as estratégias devem primar pela valorização daquilo que a atividade possui como diferencial, tais como a possibilidade de oferecer o produto a fresco ou "direto do pescador" nas bancas e mercados comunitários, especialmente durante a temporada de verão.

\footnotetext{
${ }^{4}$ A proposta foi desenvolvida pelo IPARDES - Instituto Paranaense de Desenvolvimento Econômico e Social - e foi executada com recursos do Governo Federal e do Banco Mundial. A responsabilidade de assessorar os pescadores na condução da organização foi delegada à EMATER.
} 
Na baixa temporada, podem ser promovidas feiras itinerantes em outras regiões do estado, o que trouxe resultados satisfatórios no tempo de funcionamento da COOPESPAR. No mesmo período, valendo-se da presença crescente de turistas em fins de semana e em feriados prolongados, poderiam ser realizados eventos para promover o consumo e a divulgação dos produtos locais. O calendário dos eventos poderia acompanhar as principais "safras" de pescado. Por exemplo, poderiam ser realizados festivais para a valorização do camarão-branco, do linguado, da tainha, da cavala, etc. Além de servir para a comercialização, os eventos seriam importantes plataformas de resgate e divulgação da cultura pesqueira local.

Todas essas estratégias podem ser acompanhadas de ações para a promoção do comércio justo, estimulando-se a compra de pescado produzido por pescadores de pequena escala que se esforçam para produzir de forma justa, solidária e ecologicamente prudente.

\subsection{Empoderamento dos pescadores}

A existência de um consolidado paradigma de individualismo, assim como as dificuldades e desestímulos às ações coletivas em prol de objetivos comuns, constituem importantes obstáculos para a construção de novas formas de organização social da produção e comercialização do pescado em Pontal do Paraná. Desse modo, esse tipo de jornada requer consistentes esforços para o empoderamento da classe pesqueira local.

Uma estratégia interessante seria criar oportunidades para o aprendizado social a partir das experiências de organização dos pescadores locais, tanto daquelas de sucesso, que apontam direções profícuas e mostram que a cooperação pode valer a pena, quanto daquelas fracassadas, que representam uma importante oportunidade de aprendizado. No primeiro caso, poderiam ser promovidas discussões sobre as experiências de mercados comunitários e portos coletivos, ou mesmo sobre os elementos de sucesso de algumas unidades produtivas locais. No caso das experiências não exitosas, seria crucial abordar o caso da extinta COOPESPAR, buscando não apenas identificar e aprender com os erros, mas também desfazer alguns estigmas e mitos decorrentes do insucesso dessa organização econômica, tais como o de que os pescadores são irreversivelmente individualistas e o de que as estratégias de cooperação não são viáveis no caso da pesca de Pontal do Paraná. Seria interessante também promover a interação dos pescadores locais com experiências de organização coletiva realizadas em outras regiões.

Situações como essa também exigem que, de início, se demonstre que tais mudanças não significam a perda da liberdade individual ou o cerceamento das possibilidades de ascensão social e econômica dos envolvidos, mas que, pelo contrário, para muitos deles elas podem significar a libertação em relação às formas de subordinação a que estão submetidos (Singer, 2002).

$\mathrm{O}$ estímulo à participação deve ser apoiado por esforços consistentes de assistência técnica e de extensão pesqueira. Estes podem ser ancorados em sistemas participativos de coleta e análise de informações sobre a economia pesqueira local, os quais podem dar suporte a discussões sobre os custos e benefícios da constituição de unidades produtivas fundadas em relações mais cooperativas e igualitárias, bem como sobre as estratégias mais eficientes de produção e comercialização.

As estratégias de empoderamento também devem promover o aumento da capacidade dos pescadores influenciarem na construção de políticas públicas para o setor e atuarem na defesa de seus interesses frente a elementos externos com potencial para interferir nos resultados obtidos pela pesca local. Um bom exemplo são as atividades com capacidade de impactar e subtrair os recursos naturais que sustentam o seu modo de vida, tais como a pesca realizada em outras regiões e outras formas de uso e ocupação do ambiente costeiro.

\section{Considerações finais}

O presente estudo de caso revela a importância de considerar a questão econômica no processo de gestão compartilhada da pesca. É nessa dimensão que se encontram alguns dos principais condicionantes dos padrões de competição e conflito que contribuem para a ocorrência de resultados socioeconômicos indesejáveis, como ineficiência econômica, vulnerabilidade e iniquidades distributivas. 
Não se pretende aqui a revisão ou reconstrução total da organização social da produção pesqueira local. Por hora, o que se propõe são estratégias pontuais ou intersticiais, como as propostas pela chamada "economia solidária”, que representam pequenas mudanças em direção a relações de produção mais cooperativas na tentativa de melhorar a condição daqueles que estão desfavorecidos pelo modo de produção vigente (Singer, 2002).

Também é importante esclarecer que propor maior atenção às dinâmicas econômicas que influenciam o comportamento dos pescadores, bem como à busca de melhorias na sua condição de produtores mercantis, não significa atribuir menos importância ou sacrificar a questão da conservação dos recursos. Pelo contrário, estas ações são essenciais para a compreensão e tratamento de uma forte estrutura de incentivos para o uso abusivo e destrutivo dos recursos naturais que sustentam a pesca do município.

A constituição de unidades produtivas em regime de parceria ou com propriedade coletiva dos instrumentos pode atenuar a competição entre os pescadores locais, reduzindo a intensidade da corrida por maior produtividade e, consequentemente, a pressão sobre os recursos naturais. A estratégia também pode reduzir os casos em que condições limitadas de produção e situações de dificuldade econômica incentivam usos destrutivos.

Melhorar as condições de comercialização, investindo na diminuição da intermediação e na valorização dos produtos é, sem dúvida, uma forma de aumentar a eficiência econômica sem intensificar a exploração dos recursos. Mais do que isso, a medida pode fazer com que os pescadores substituam parte do tempo de trabalho dedicado às capturas pelo trabalho na comercialização, diminuindo o esforço de pesca.

A criação de produtos locais com valores de uso diferenciados, contornando a competição com formas mais tecnificadas e intensivas de produção, também pode diminuir os incentivos à intensificação. A diminuição da concorrência externa também pode possibilitar o desenvolvimento de estratégias coletivas de diminuição do esforço de pesca para conter a oferta e evitar quedas expressivas nos preços, contribuindo para a conservação da base de recursos.

Ao contribuírem para a melhoria da condição de produtor e da qualidade de vida dos pescadores, as ações voltadas para a dimensão econômica podem reduzir significativamente o acirrado conflito entre os usuários locais e gestores, diminuindo os custos de transação do processo de gestão compartilhada e contribuindo para a criação de uma atmosfera favorável à gestão dos recursos.

Por fim, cumpre esclarecer que enfatizar a necessidade de atenção às dinâmicas econômicas não implica reduzir a importância das instituições, muito menos menosprezar as contribuições teóricas e práticas dos estudos sobre processos de criação institucional para o manejo dos recursos. Mesmo em um contexto de mudança nas formas de produzir e vender o pescado, tais como aquelas propostas neste artigo, as instituições para a gestão dos recursos teriam um papel fundamental na gestão pesqueira, contribuindo para o tratamento de assimetrias nas relações de poder, para resolução de conflitos, para distribuição equitativa dos custos e benefícios, para a construção de estratégias coordenadas de conservação dos recursos e para a repressão às atitudes de usuários oportunistas, individualistas e com visão limitada ao curto prazo.

\section{Agradecimentos}

Aos pescadores, pescadoras e comerciantes de pescado de Pontal do Paraná, pela acolhida, pela confiança e pelo conhecimento compartilhado. À Jacob Gaeti Júnior e Astrogildo José Gomes de Melo, da EMATER e à Licio Domit, do IBAMA, pela prestatividade durante as entrevistas. À Humberto Zontini Malheiros, pela elaboração dos mapas apresentados neste artigo. 


\section{Referências}

Andriguetto-Filho J. M.; Chaves, P. T.; Santos, C.; Liberati, S. A. Diagnóstico da pesca no litoral do estado do Paraná. In: Isaac, V. J.; Martins, A. S.; Haimovici, M.; Andriguetto-Filho, J. M. (Orgs.) A pesca marinha e estuarina do Brasil no inicio do século XXI: recursos, tecnologias, aspectos socioeconômicos e institucionais. Universidade Federal do Pará, Belém, Brasil, p. 117-140, 2006.

Berkes, F.; Mahon, R.; McConney, P.; Pollnac, R.; Pomeroy, R. Managing small-scale fisheries: alternative directions and methods. International Development Research Centre, Ottawa, Canada, 2001.

Bernardo, C.; Cattani, A. P.; Spach, H. L.; Schwarz Junior, R.; Stoiev, S. B. A captura incidental de cienídeos em arrasto experimental com rede de portas utilizada na pesca do camarão sete-brabas (Xiphopenaeus kroyeri) no estado do Paraná, Brasil. Arquivos de Ciências do Mar, 44, 98-105, 2011.

Brandini, F, P. Marine biodiversity and sustainability of fishing resources in Brazil: a case study of the coast of Paraná state. Regional Environmental Change, 13, 1-11, 2013.

Chaves, P.T.; Cova-Grando, G.; Calluf, C. Demersal ichthyofauna in a continental shelf region on the south coast of Brazil exposed to shrimp trawl fisheries. Acta Biológica Paranaense, 32(1), 69-82, 2003.

Foladori, G.; Melazzi, G. Economía de la sociedad capitalista y sus crisis recurrentes. Montevideo: CSEAM - Universidad de la República, 2009.

Marx, K. El capital. Tomo I, Vol. 1 e Vol. 2. México: Siglo XXI, 1987.

IAP- Instituto Ambiental do Paraná. Portaria $n^{\circ} 85,19$ de junho de 2009. Curitiba: DOE de 25/6/2009.

IBAMA - Instituto Brasileiro de Meio Ambiente e recursos Naturais renováveis. Portaria $n^{\circ} 12$, de 20 de março de 2003. Brasília: DOU de 21/03/2003.

IBAMA - Instituto Brasileiro de Meio Ambiente e recursos Naturais renováveis. Instrução Normativa $n^{\circ} 166$, de junho de 2007. Brasília: DOU de 19/07/2007.

IBAMA - Instituto Brasileiro de Meio Ambiente e recursos Naturais renováveis. Portaria $n^{\circ} 171$, de maio de 2008. Brasília: DOU de 12/05/2008.

IBGE - Instituto Brasileiro de Geografia e Estatística. Censo demográfico 2010. Síntese das Informações. Disponível em: $<$ http://cod.ibge.gov.br/5tck>. Acesso em mar. 2014.
ICLARM - International Centre for Living Aquatic Resources Management. Analysis of Co-Management Arrangements in Fisheries and related Coastal Resources: A Research Framework. Coastal Resources Co-Management Research Project Core Staff. Institute of Fisheries Management and Coastal Community Development (IFM), 1998.

IPARDES. Instituto Paranaense de Desenvolvimento Econômico e Social. Zoneamento do Litoral Paranaense. Fundação Édson Vieira, 1989.

Lana, P. C.; Marone, E.; Lopes, R. M.; Machado, E. C. The subtropical estuarine complex of Paranaguá Bay. In: Seeliger, U.; Kjerfve, B. (Org.) Coastal Marine Ecosystems of Latin America. Berlin: Springer Verlag, p. 132-145, 2001.

MMA - Ministério do Meio Ambiente. Instrução Normativa ${ }^{\circ}$ 5, de maio de 2004. Brasília: DOU de 28/05/2004.

MMA - Ministério do Meio Ambiente; MPA - Ministério da Pesca e Aquicultura. Instrução Normativa Interministerial $n^{\circ}$ 12, de 22 de agosto de 2012. Brasília: DOU de 24/ 08/2012.

Noernberg, M. A.; Angelotti, R.; Caldeira, G. A.; Sousa, A. F. R. Determinação da sensibilidade do litoral paranaense à contaminação por óleo. Brazilian Journal of Aquatic Science and Technology, 12, 49-59, 2008.

Oakerson, R. Analyzing the commons: a framework. In: Bromley, D.W. (Ed.). Making the commons work: theory, practice, and policy. San Francisco, California: ICS Press, p. 41-59, 1992.

Ostrom, E. Governing the Commons: the evolution of institutions for collective action. Cambridge University Press, 1990.

Ostrom, E. The Rudiments of a Theory of the Origins, Survival, and Performance of Common Property Institutions. In: Bromley, D. W. (Ed.). Making the commons work: theory, practice, and policy. San Francisco, Califórnia: ICS Press, p. 293-316, 1992.

Pierri, N. O Litoral do Paraná: entre a riqueza natural e a pobreza social. Desenvolvimento e Meio Ambiente, 8, 25-41, 2003.

Pierri, N.; Angulo, R. J.; Souza, M. C.; Kim, M. K. A ocupação e o uso do solo no litoral paranaense: condicionantes, conflitos e tendências. Desenvolvimento e Meio Ambiente, 13,137-167, 2006.

Pomeroy, R. S.; Williams, M. J. Fisheries co-management and small-scale fisheries: a policy brief. International Center for Living Aquatic Resources Management, Manila. 15 p., 1994. 
Pomeroy, R. S.; Rivera-Guieb, R. Fishery co-management: a practical handbook. IDRC/CADI, 2006.

Quivy, R.; Campenhoudt, L. V. Manual de investigações em ciências sociais. Lisboa: Ed. Gradiva, 1992.

Seixas, C. S. Abordagens e técnicas de pesquisa participativa em gestão de recursos naturais. In: Vieira, P. F.; Berkes, F.; Seixas, C.S.; (Orgs.). Gestão Integrada e Participativa de Recursos Naturais. Florianópolis: APED, p. 73-105, 2005.

SEMA. Secretaria de Estado do Meio Ambiente e Recursos Hídricos. Resolução $n^{\circ}$ 016/2009.

SETU - Secretaria de Estado do Turismo. Estudo de demanda turística do Litoral. Passageiros. Estatísticas do Turismo. 2006.
Disponível em: www.pr.gov.br/ turismo/estatisticas.shtml> Acesso em: ago.2007.

Singer, P. Introdução à economia solidária. São Paulo: Editora Fundação Perceu Abramo, 2002.

Singh, S. Some critical issues in community participation In: Vieira, P. F. (Org.). Conservação da diversidade biológica e cultura, em zonas costeiras: Enfoques e experiências na América Latina e no Caribe. APED. Florianópolis, p.75-113, 2003.

Thomson, J. T.; Feeny, D.; Oakerson R. J. Institutional dynamics: the evolution and dissolution of common property resource management. In: Bromley, D. W. (Ed.). Making the commons work: theory, practice, and policy. San Francisco, California: ICS Press, p.129-160, 1992. 